\section{Japan ends its isolation}

\section{Tokyo}

TOKYO University this month opened the first high-capacity computer link between Japan's national research institutes and scientific computer networks in the United States and other parts of the world. The link is expected to stimulate development of Japan's primitive computer networks and may also help to break down some of the bureaucratic barriers that exist between Japan's research institutes.

The new computer link, the Todai (Tokyo University) International Science Network, was established after Professor T. Nielson of the Department of Computer Information Science at the University of Hawaii approached Tokyo University's faculty of science late last year in search of a landing point in Japan for his Pan-Pacific Computer Network.

Unable to get government funding for the network, Akiyoshi Wada, dean of the faculty of science, with the help of Ken Sakamura of the university's department of information science, arranged for the giant computer manufacturer Fujitsu to support the project. Fujitsu has donated workstations for the network worth about $¥ 30$ million $(\$ 210,000)$ and for the next 18 months the computer company will cover the 1-million-yen-a-month cost of leasing a high-capacity (64 kilobits per second) line between Tokyo University and Hawaii University.

The network will provide access to most OPTICAL FIBRE LINKS

\section{Pacific cable breaks}

\section{Tokyo}

THE new trans-Pacific optical-fibre cable (TPC-3) linking Japan and the United States has suffered a serious break in transmission only months after it began operations.

TPC-3 is the first optical-fibre link between the United States and Japan and began leased-line and telephone services in April. But on 18 July the line broke down and transmission was not restored until 22 August. The breakdown, which has not been reported in Japan, caused problems for workers at Tokyo University who are planning to use the cable for a computer link with the University of Hawaii (see above). Instead, the university has been using satellite transmission.

The break was traced to a point $4,500 \mathrm{~km}$ from Hawaii at a depth of about 5,000 metres. American Telephone and Telegraph (AT \& T), which jointly operates the cable with Kokusai Denshin Denwa (KDD), replaced $60 \mathrm{~km}$ of cable and a repeater, according to Shigeru Minatani of KDD. The cause of the break is suspected to be a faulty repeater.

David Swinbanks of the scientific networks in the West such as HEPNET, used by high-energy physicists, SPAN, a network for astrophysicists, and LIFENET, used by life scientists. And Japanese scientists will be able to log onto computers in research centres in the United States and Europe as if the computer were "in their own room", according to Tsuneyoshi Kamae, chairman of the committee which established the network. Similarly, Western scientists will be able to $\log$ onto computers in Japan.

About ten national research institutes, including the High Energy Physics Laboratory (KEK), the Institute of Physical and Chemical Research (RIKEN), the Institute of Space and Astronautical Science (ISAS) and the Institute of Genetics, are expected to use the network, and these institutes and Tokyo University will pay for the network's running costs when Fujitsu's support runs out.

Surprisingly, the major running cost may not be the link with Hawaii but rather some of the domestic links in the network. The opening up of Japan's international telecommunications market to two new companies, including one backed by Cable and Wireless of the United Kingdom, has forced the former monopoly Kokusai Denshin Denwa (KDD) dramatically to reduce its rates. Even during the few months of planning the network, KDD reduced the price of the Tokyo-Hawaii link by more than 20 per cent.

But domestic telecommunication rates are still maintained at inflated levels by Nippon Telegraph and Telephone (NTT), despite the recent establishment of several small competing domestic telecommunication companies. For example, leasing an NTT line between Tokyo University and the Institute of Genetics in Mishima, a distance of about $120 \mathrm{~km}$, costs more than half as much as the $10,000-\mathrm{km}$ link to Hawaii.

Organizers of the new network hope to circumvent this problem by using the computer network of the National Center for Science Information System (NCSIS) which links Japan's universities and interuniversity research institutes. NCSIS charges much lower rates than NTT but the capacity of its network $(9,600$ bits per second) is too limited. Tokyo University and KEK researchers, however, are requesting that it be upgraded to 48 kilobits per second.

Kamae says that computer networks in Japan lag far behind those of the United States and Europe. Computer companies and government ministries, he says, still maintain a "wartime attitude" about computers. They build huge mainframes "like the battleship Yamato" but not the small workstations that best suit computer networks. The workstations supplied by Fujitsu are made under licence from the US company Sun.

The Japanese government has built many huge "monuments" to science in the form of institutes and universities, Wada says, but "just as the navy built the battleship Yamato and forgot about logistics and communications", the government has failed to link Japan's research organizations into a coherent whole.

At the root of the problem is interministry and inter-agency rivalry which prevents institutes and researchers belonging to different government organizations from interacting. But the new computer network seems likely to break down some of these barriers.

RIKEN is anomalous among the organizations joining the new network because it belongs to the Science and Technology Agency; the other institutes and the University of Tokyo are all affiliated to the Ministry of Education, Science and Culture (MESC). RIKEN will not be able to use the MESC-funded NCSIS network. Instead, a more expensive NTT line will be used. But by building up the number of users of the Todai network, Wada and Kamae hope to bring down the costs of subscription to a level that any institute or university in Japan can easily afford without recourse to special government support.

Davld Swinbanks NUCLEAR POWER

\section{Alarm at plants}

Paris

SERIOUs anomalies have been found this month in safety devices built into two French nuclear electricity generating plants. In both cases, temporary modifications to safety circuits were left in place after routine maintenance, rendering them essentially ineffective in the case of an accident. The first anomaly was detected earlier this month at the Dampierre plant.

Two plugs, fitted for tests on piping in the containment architecture, were not subsequently removed. Circuits designed to reduce the risk of an explosion in the event of a major accident were thus apparently compromised.

The most recent fault was discovered last week at the Gravelines reactor and was rated as a Class 3 incident (on a scale of six). Three safety valves, designed to prevent pressure build-up within the reactor in the case of an incident, were fitted with screws of the wrong type. It emerges that the screws had been in place since June 1988. The central nuclear installation safety service (SCSIN) has said that it is concerned by this apparent negligence. Meanwhile, Electricité de France, which operates the reactors, has ordered immediate checks at all its nuclear generator sites. Peter Coles 